\title{
Modeling of High-altitude Atmospheric Dispersion Using Climate and Meteorological Forecast Data
}

\author{
Principal Investigators: $\quad$ L. G. Glascoe \\ H. - N. S. Chin
}

April 2005

U.S. Department of Energy

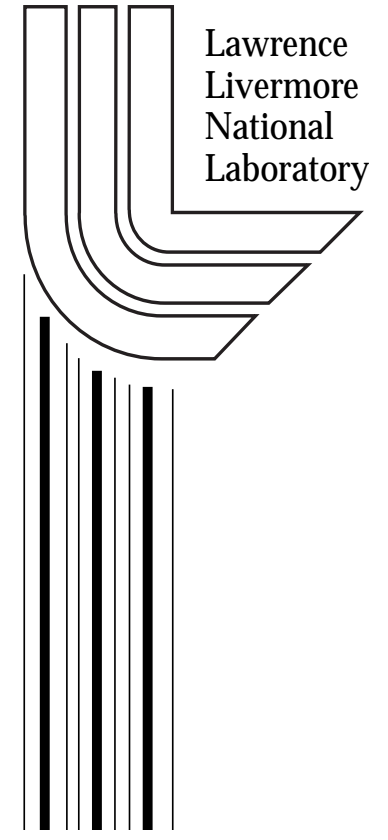




\section{DISCLAIMER}

This document was prepared as an account of work sponsored by an agency of the United States Government. Neither the United States Government nor the University of California nor any of their employees, makes any warranty, express or implied, or assumes any legal liability or responsibility for the accuracy, completeness, or usefulness of any information, apparatus, product, or process disclosed, or represents that its use would not infringe privately owned rights. Reference herein to any specific commercial product, process, or service by trade name, trademark, manufacturer, or otherwise, does not necessarily constitute or imply its endorsement, recommendation, or favoring by the United States Government or the University of California. The views and opinions of authors expressed herein do not necessarily state or reflect those of the United States Government or the University of California, and shall not be used for advertising or product endorsement purposes.

This work was performed under the auspices of the U. S. Department of Energy (DOE) by the University of California, Lawrence Livermore National Laboratory (LLNL) under Contract No. W-7405-Eng-48. Funding for this effort is provided by the US Defense Threat Reduction Agency and was performed under the auspices of the US Department of Energy by the University of California, Lawrence Livermore National Laboratory under Contract No. W-7405-Eng-48. Model development and preliminary work necessary for simulations discussed herein was done in part for Project 03-ERD039, funded by the Laboratory Directed Research and Development Program at LLNL. 
Preface: Lawrence Livermore National Laboratory (LLNL) is a national security laboratory whose mission is to solve complex scientific and technological problems of national importance. The hallmark of this laboratory is our ability to translate basicscience concepts into technologies that solve complicated real-world problems and expand the boundaries of fundamental science. LLNL has long-standing experience in multidisciplinary integration and the computer simulation of complex systems. We assure that our unique capabilities contribute most effectively by emphasizing collaborative activities, in particular collaborations with other laboratories, partnerships with industry, collaborations with academia, partnerships with other federal agencies, and international partnerships. A detailed description of LLNL programs and plans can be found in the Institutional Plan, FY2002-2007, UCAR-10076-20.

The LLNL National Atmospheric Release Advisory Center (NARAC) provides tools and services that map the probable spread of hazardous material accidentally or intentionally released into the atmosphere. NARAC provides atmospheric plume predictions in time for an emergency manager to decide if taking action is necessary to protect the health and safety of people in affected areas. Located at LLNL, NARAC is a national support and resource center for planning, real-time assessment, emergency response, and detailed studies of incidents involving a wide variety of hazards, including nuclear, radiological, chemical, biological weapons, as well as those from natural emissions.

\section{Introduction}

Ground deposition resulting from the release aloft of stable drops is of interest for both national and homeland security and is a problem driven by both source conditions and meteorological conditions. Liquid mass released at high altitudes and at supersonic velocities break up in a complex manner yielding a stable droplet size that is subsequently entrained, dispersed, and then deposited on the ground according to the local regional-scale meteorology. In the case of drop release at lower near-ground altitudes, droplets undergo subsequent dispersion and relatively prompt deposition. In the case of higher altitude drop release under rarefied conditions experience greater dispersion followed by relatively delayed deposition. As meteorological conditions are one of the principal sources of uncertainty to this problem, the necessity of quantifying wind-field uncertainty and of incorporating an up-to-date and accurate high-altitude meteorological data-feed is essential for predicting the location, extent, and eventual consequence associated with any high-altitude release. The local temporally and spatially varying meteorology governs the transport and dispersion of the droplets upon release from the source. The work presented in this report focuses on the role of high-altitude meteorology and resultant transport/dispersion of droplets after release; this preliminary exercise only initiates the necessary testing of NARAC's compatibility with specific higher altitude datasets to model the fate and transport of a high altitude release.

In this study we imported a high altitude meteorological forecast dataset (G2S) and a high altitude climatological dataset from the US Naval Research Laboratory (NRL) in Washington, D.C. into the NARAC modeling system for simulating the transport and ground-effects of a high altitude release ( $\sim 60$ to $100 \mathrm{~km})$. This importation complements an earlier importation of forecast data from NASA, the GEOS-4 dataset. This study only considers the current capabilities of the NARAC modeling system and the 
importation/application of these particular datasets on the current NARAC modeling system. Toward this end the imported meteorological and climatological data were input to NARAC's atmospheric data assimilation model, ADAPT, which ensures massconsistency and estimates turbulent diffusion parameters so that the transport and fate of high altitude chemical releases can be modeled on NARAC's Lagrangian particle tracking code, LODI.

\section{Objectives, Goals and Tasks}

The overall objective of this study is to provide a demonstration of capability for importing both high altitude meteorological forecast and climatological datasets from NRL into the NARAC modeling system to simulate high altitude atmospheric droplet release and dispersion. The altitude of release for the proposed study is between 60 and $100 \mathrm{~km}$ altitude. As either standard climatological data (over a period of 40 years) or daily meteorological forecasts can drive the particle dispersion model, we did a limited comparison of simulations with meteorological data and simulations with climatological data.

The modeling tools used to address this problem are the National Atmospheric Release Advisory Center (NARAC) modeling system at LLNL which are operationally employed to assist DOE/DHS/DOD emergency response to an atmospheric release of chemical, biological, and radiological contaminants. The interrelation of the various data feeds and codes at NARAC are illustrated in Figure 1. The NARAC scientific models are all verified to both analytic solutions and other codes; the models are validated to field data such as the Prairie Grass study (Barad, 1958). NARAC has multiple real-time meteorological data feeds from the National Weather Service, from the European Center for Medium range Weather Forecasting, from the US Navy, and from the US Air Force. NARAC also keeps a historical archive of meteorological data partially for research purposes. The codes used in this effort were the Atmospheric Data Assimilation and Parameterization Techniques (ADAPT) model (Sugiyama and Chan, 1998) and a development version of the Langrangian Operational Dispersion Integrator (LODI) model (Nasstrom et al., 2000). The use of the NASA GEOS-4 dataset required the use of a development version of the Coupled Ocean/Atmosphere Mesoscale Prediction System (COAMPS) model (Hodur, 1997; Chin and Glascoe, 2004).

The specific goals of this study are the following:

- Goal 1: Confirm data compatibility of NRL meteorological and climatological data for NARAC models. Import both high altitude meteorological forecasts and high altitude climatological data provided by NRL into the NARAC system.

- Goal 2: Run ADAPT and LODI transport/dispersion codes for one scenario on imported meteorological forecast and climatological data.

- Goal 3: Provide documentation of the effort.

The following tasking description gives both the context and manner in which the goals listed above were accomplished:

- Task 1: We had discussions with NRL personnel, notably Stefan Thonnard and Doug Drob, to confirm the data compatibility of the data that we will be 
importing for use. Data up to $100 \mathrm{~km}$ in altitude was provided and imported into the NARAC modeling system.

- Task 2: The ADAPT atmospheric data assimilation model was used to take data from NRL and provide mass-consistent three-dimensional time-varying wind fields for the NARAC Langrangian particle tracking code, LODI. A test version of LODI, developed to consider rarefied conditions, higher altitude turbulence, and high initial particle speeds, was used run on the ADAPT output.

- Task 3: The results of the proof-of-concept simulations under time-varying meteorological forecasts and under climatological wind fields are compared and documented in this brief report discussing the capability of the NARAC modeling system for importing and using the high altitude datasets from NRL. A limited assessment of the difference between dispersion results on the different data sets is made.
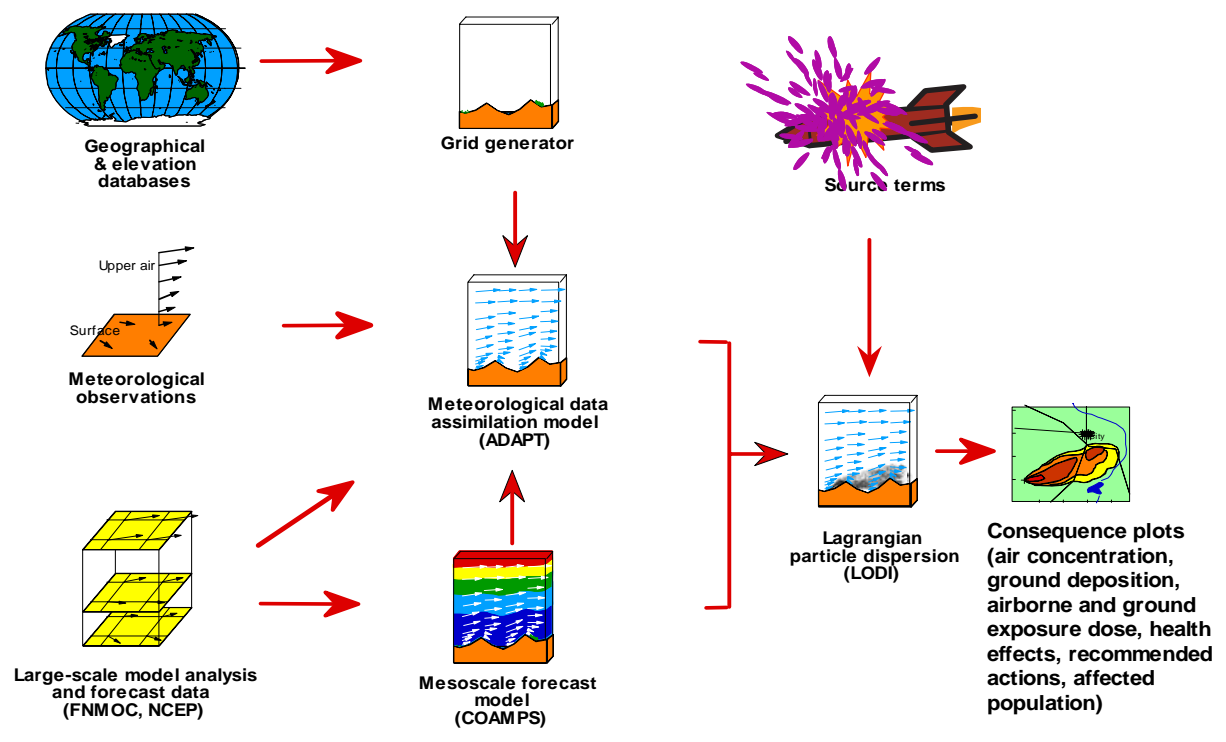

Figure 1. Interrelation of NARAC data feeds and simulation models. Of particular note for this effort are the COAMPS forecast model, the ADAPT meteorological data assimilation model, and the LODI Lagrangian particle-tracking model.

\section{Higher Altitude Simulations Using LODI}

\section{High-altitude Modifications to LODI and COAMPS}

LLNL/NARAC capabilities for high altitude releases were initially developed by a twoyear LLNL Laboratory Directed Research and Development (LDRD) project (Roxana Greenman and Lee Glascoe, Principal Investigators, 2002-2004). To properly simulate dispersal of droplets at high altitude, three significant modifications to the NARAC/LODI particle tracking code were made: (1) inclusion of dynamic momentum for each particle, (2) inclusion of rarefied and high speed drag conditions, and (3) incorporation of higher altitude turbulence. Droplets released at a high altitude are often associated with high 
initial momentum, i.e., an initial momentum much greater than the terminal settling velocity and need to account for dynamic momentum due to rapidly changing terminal settling velocities. For lower atmospheric releases, the density of the atmosphere slows supersonic water droplets very quickly, thus rendering initial momentum to having a negligible overall contribution to the atmospheric dispersal of the droplet relative to wind-dispersal. However, at higher altitudes where the atmospheric density is low, water droplets, particularly large water droplets, can travel a large distance before aerodynamic drag slows the droplet to terminal velocity. To accommodate these higher velocities for the higher altitude problem, a dynamic momentum capability has been added and tested for the LODI particle tracking code. The change is simply the inclusion of a transient three-dimensional momentum equation. The drag-laws were updated to accommodate the rarefied conditions of higher altitudes and higher Mach numbers by introducing a modified Cunningham correction (Crowe et al., 1998). All of these changes in LODI were verified to analytic and semi-analytic solutions. Turbulence below the planetary boundary layer is modeled as a dispersive transport parameter that is anisotropic vertically and horizontally, and varies in time. This turbulence diffusivity is a function of the friction velocity, the boundary layer height, and the mixing length. Turbulence diffusivity is presently modeled as isotropic and constant in time above the boundary layer. This is not realistic as there are two types of turbulence that should be represented in the upper atmosphere: (1) clear-air turbulence, CAT, in the presence of wind shear; and (2) non-linear interactions in breaking gravity waves. Methods of incorporating this turbulence have been proposed by Diehl (1994) and Pluene (1990). For this study, these effects have been incorporated into vertical turbulence diffusivity with a Richardson number approach for changes in vertical wind shear (Hartjenstein, 2000; Nappo, 2002).

The GEOS-4 dataset of NASA was incorporated into a development version of COAMPS at NARAC (Chin and Glascoe, 2004). The development version is modified to make use of the higher altitude coverage provided by the GEOS-4 dataset by extending COAMPS beyond its conventional focus of prediction below $32 \mathrm{~km}$ altitude (see Figure 2). Toward this end, the first step of modification is to extend the climatology specification from $0.2 \mathrm{mb}(\sim 59 \mathrm{~km})$ to $0.0003 \mathrm{mb}(\sim 104 \mathrm{~km})$. Secondly, the formulation to compute saturated mixing ratio of water vapor was also changed. The calculation of saturated moisture pressure in COAMPS is based on a look-up table, which uses temperature dependence. However, this approach would fail for the high-altitude forecast above $32 \mathrm{~km}$ since the temperature in the stratosphere would continuously increase to the level near the stratopause $(\sim 47 \mathrm{~km})$ with the magnitude as high as the ones seen near the surface. Therefore, COAMPS would significantly over-estimate the saturated moisture pressure in the higher stratosphere such that the saturated moisture pressure becomes smaller than the air pressure. The resulting negative mixing ratio of water vapor would cause the crash of microphysics calculation. This problem is solved by using Teten's formulation (Chin, 1994; Chin et al., 1995) to compute the saturated mixing ratio of water vapor directly. The modified formulation uses both air temperature and pressure so that the new scheme can distinguish the lower troposphere from the higher stratosphere in the calculation of saturated mixing ratio of water vapor. 


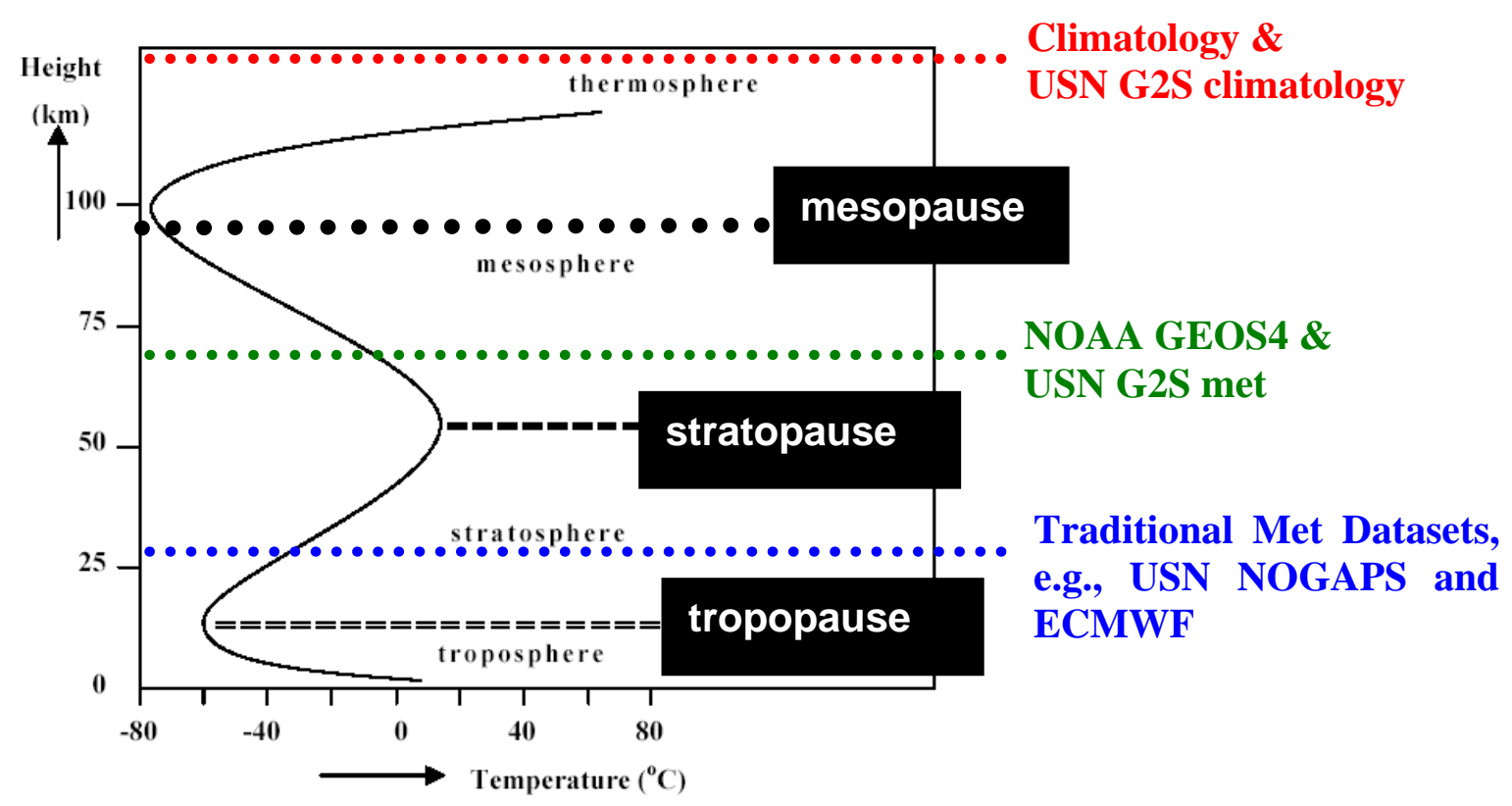

Figure 2. The vertical temperature profile in the atmosphere, delineating the extent of the troposphere, stratosphere and mesosphere. Indicated are the altitudes to which the various high altitude data is valid.

\section{LODI Test Simulation from 10 to $80 \mathrm{~km}$}

Higher altitude release is best examined in terms of two liquid drop sizes: large (defined as greater than $1 \mathrm{e}-4 \mathrm{~m}$ in diameter) and small (defined as less than $1 \mathrm{e}-4 \mathrm{~m}$ in diameter). Large drop particles released at high altitudes (greater than $40 \mathrm{~km}$ ) will display a notable amount of horizontal displacement due to the initial momentum of the particle and drop out of the sky relatively quickly even at altitudes of $100 \mathrm{~km}$. Conversely, small particles at high altitudes (greater than 40km) are more dominated by synoptic meteorological conditions. Long-term atmospheric simulations of Gobi desert dust storms demonstrate how small particles (less than $5 \mathrm{e}-5 \mathrm{~m}$ in diameter) can travel significant distances in a short period of time, e.g., a simulation from the spring of 2002 showed deposition of a 20 micron particle on Japan and across the North Pacific for a Northern Asia particle release (Cameron-Smith, 2003). As a test of the new LODI capabilities, simulations at four different altitudes $(10 \mathrm{~km}, 40 \mathrm{~km}, 60 \mathrm{~km}$ and $80 \mathrm{~km})$ are examined and compared to illustrate the difference in deposition results between a relatively low-level release and a high level release for $3 \mathrm{~kg}$ of a uniform distribution of water drops ranging in diameter from 400 microns to 3200 microns. The particles are released as a point source with an initial velocity of Mach 5.3; the angle with the vertical is $40^{\circ}$ from vertical-down with the horizontal initial velocity orthogonal to the wind. A completely hypothetical (and admittedly unrealistic) steady and uniform wind of $3 \mathrm{~m} / \mathrm{sec}$ from the northwest was used, and releases with no initial momentum are compared to releases with supersonic initial momentum (Figure 3). It is noteworthy that high initial momentum only affects the heavier particles and at higher altitudes (40km or higher). The impact of initial momentum becomes very significant, particularly for larger water droplets, as the atmospheric density becomes very thin above $60 \mathrm{~km}$. 


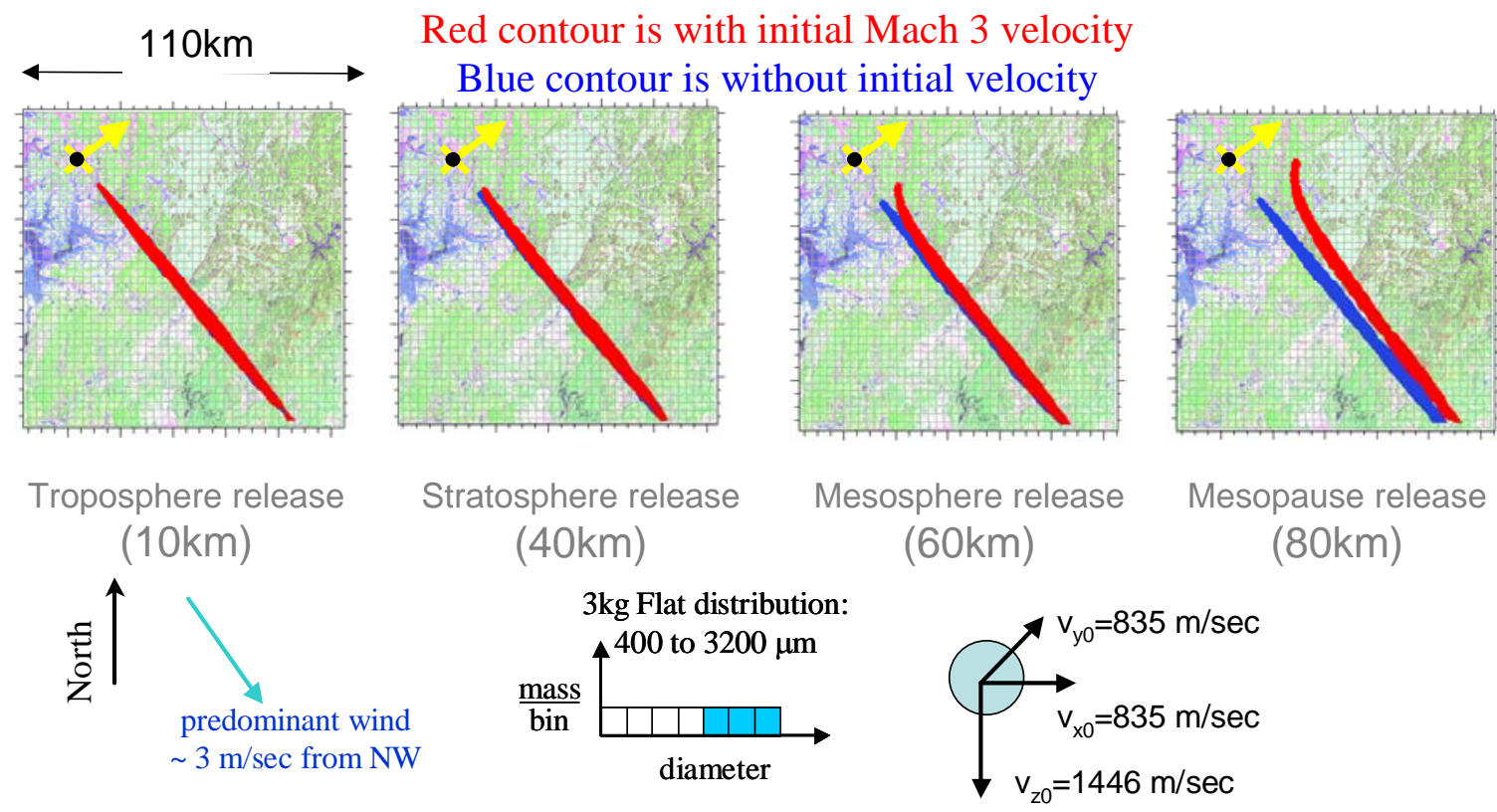

Figure 3. A NARAC/LODI set of simulations of $3 \mathrm{~kg}$ of water drops (0.40 to $3.20 \mathrm{~mm}$ diameter) released at high initial velocity at different altitudes. Note an unrealistic uniform wind of $3 \mathrm{~m} / \mathrm{sec}$ from the NW was applied throughout the domain. Shown are the $1 \mathrm{microgram} / \mathrm{m}^{2}$ deposition contours at release altitudes $10 \mathrm{~km}, 40 \mathrm{~km}, 60 \mathrm{~km}$ and $80 \mathrm{~km}$ (red is with initial momentum, blue is without). Note that the black dot in the figures is the release point and the yellow arrow indicates the horizontal direction of the incoming particle (normal to the wind).

Incorporating High Altitude Meteorology

Meteorological data at higher altitudes are much more scarce than data at lower altitudes. We acquired access to three high altitude datasets for this study: (1) the GEOS-4 high altitude data going up to $65 \mathrm{~km}$ in altitude from the NASA (DAO, 2002); (2) the G2S or 'Sky High NOGAPS' data going in excess of $120 \mathrm{~km}$ altitude from the US Navy (Drob, 2003); and (3) the NRMLMSISE-00 climatological dataset also going in excess of $120 \mathrm{~km}$ altitude from the US Navy (Picone et al., 2002). The structure of the atmosphere and the altitudes to which these different datasets are valid are illustrated in Figure 2. LODI particle tracking simulations were tested on all three datasets to confirm compatibility with the NARAC system.

\section{Simulations with NASA GEOS-4 Dataset}

Using the GEOS-4 dataset we examined a set of possible release scenarios at different altitudes at 6am on September 15, 2002. The resulting COAMPS/LODI simulations illustrate the release of a flat-distribution of particles ranging in diameters from 10 microns to 3200 microns as used for the lower altitude studies. Illustrated in Figure 4, Figure 5 and Figure 6 are the time evolution of the particle descent from 6am to 8am in three different perspectives: a three-dimensional view from the southwest, a plan view, and a side view along the east-west axis, respectively. The notable features of this simulation are (1) the rapid descent of the heavier particles, n.b., initial terminal velocity for the heavier particles is in excess of $100 \mathrm{~m} / \mathrm{sec}$, and (2) the several layers of vertical wind shear. The rapid descent of the heavier particles, e.g., the yellow colored particles 
shown in the figures, illustrates how, starting about 30 minutes after release, the largest/heaviest particles released from $65 \mathrm{~km}$ begin to deposit on the ground nearly $50 \mathrm{~km}$ east the release point. The vertical wind shear is apparent as three different structures: (1) at very high altitudes ( $\sim 50 \mathrm{~km})$ the winds are blowing from the SW (see Figure 6), (2) just above the jet-stream $(\sim 15 \mathrm{~km})$ the winds are blowing primarily from the SE (see Figure 5), (3) and just below 15km winds are blowing from the southwest (see Figure 6), nearly orthogonal to the higher altitude winds.
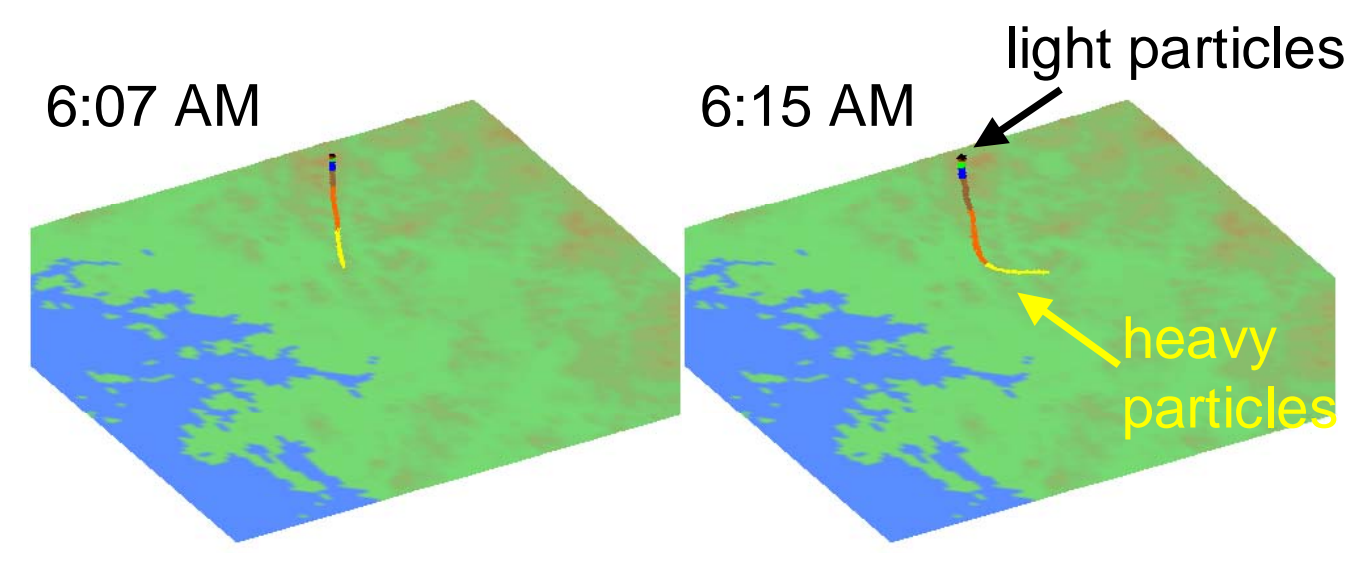

7:00 AM
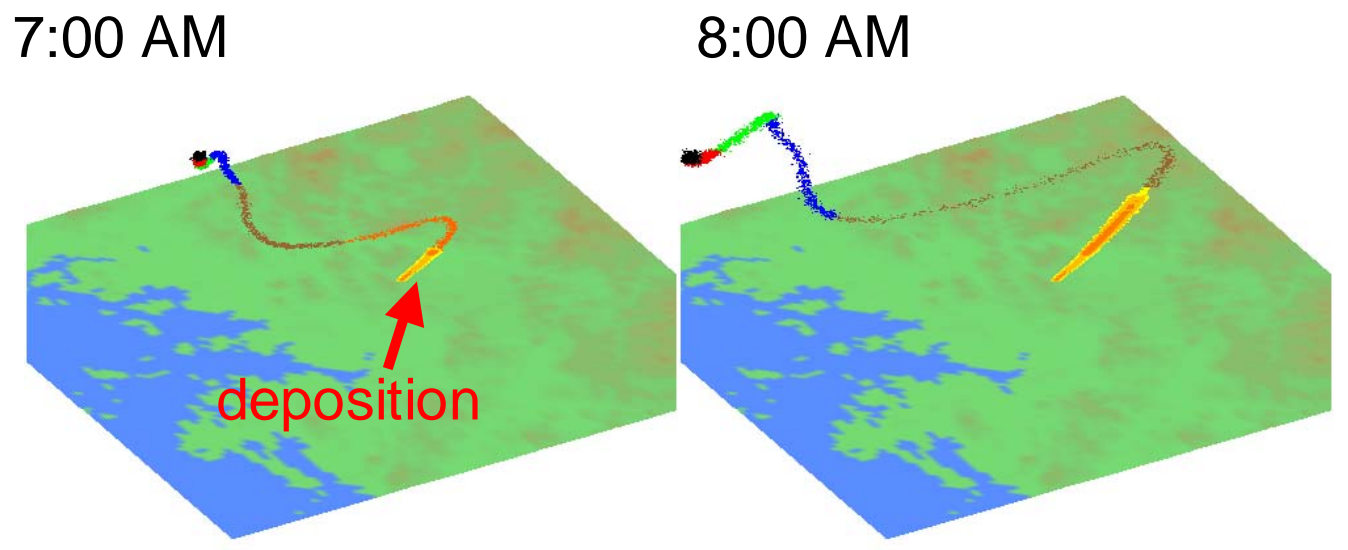

Figure 4. Three-dimensional perspective on particles and deposition as modeled with the GEOS-4 dataset from release time of 6:00am to 8:00am September 15, 2002. Release height is 65km. Note the southeasterly nature of the winds at $65 \mathrm{~km}$ versus the southwesterly nature of the winds below $10 \mathrm{~km}$. 

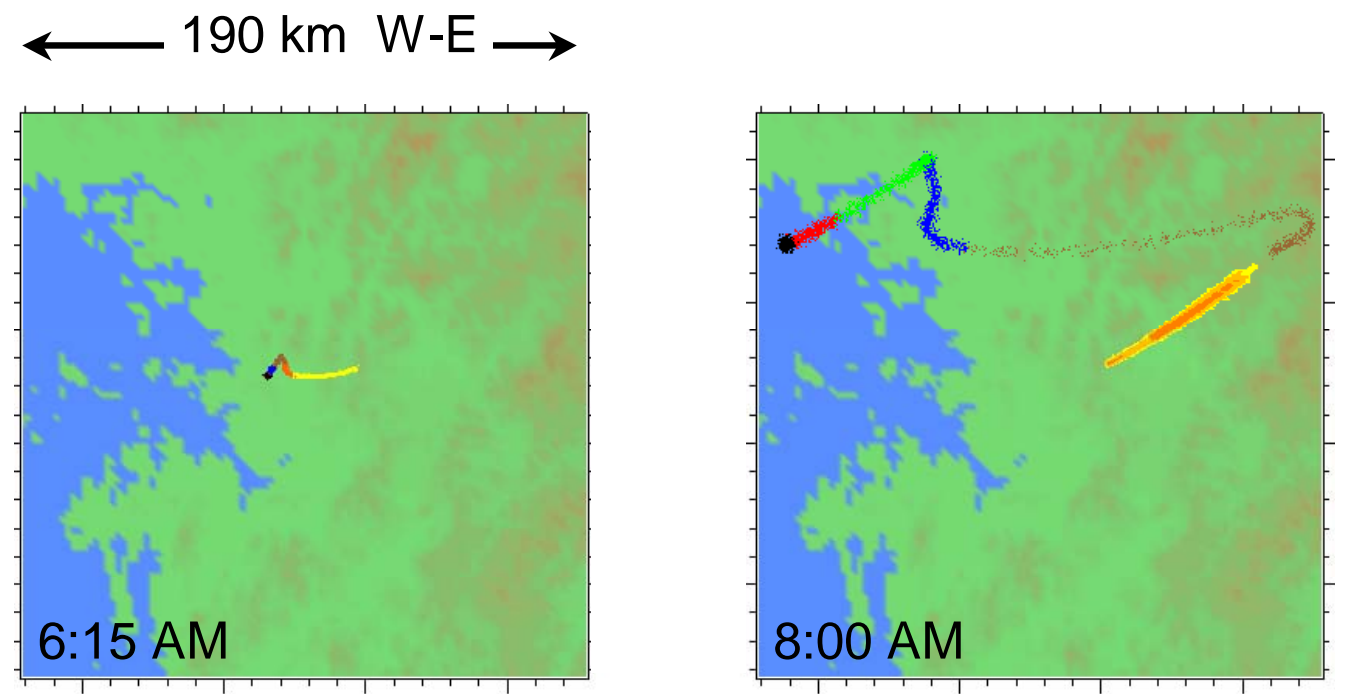

Figure 5. Plan view perspective on particles and deposition as modeled with the GEOS-4 dataset from release time of 6:00am to 8:00am September 15, 2002. Release height is 65km. Note the windshear with lighter particles aloft (black and red) blowing to the northwest and heavier particles (yellow and brown) blowing at a lower altitude to the northeast.
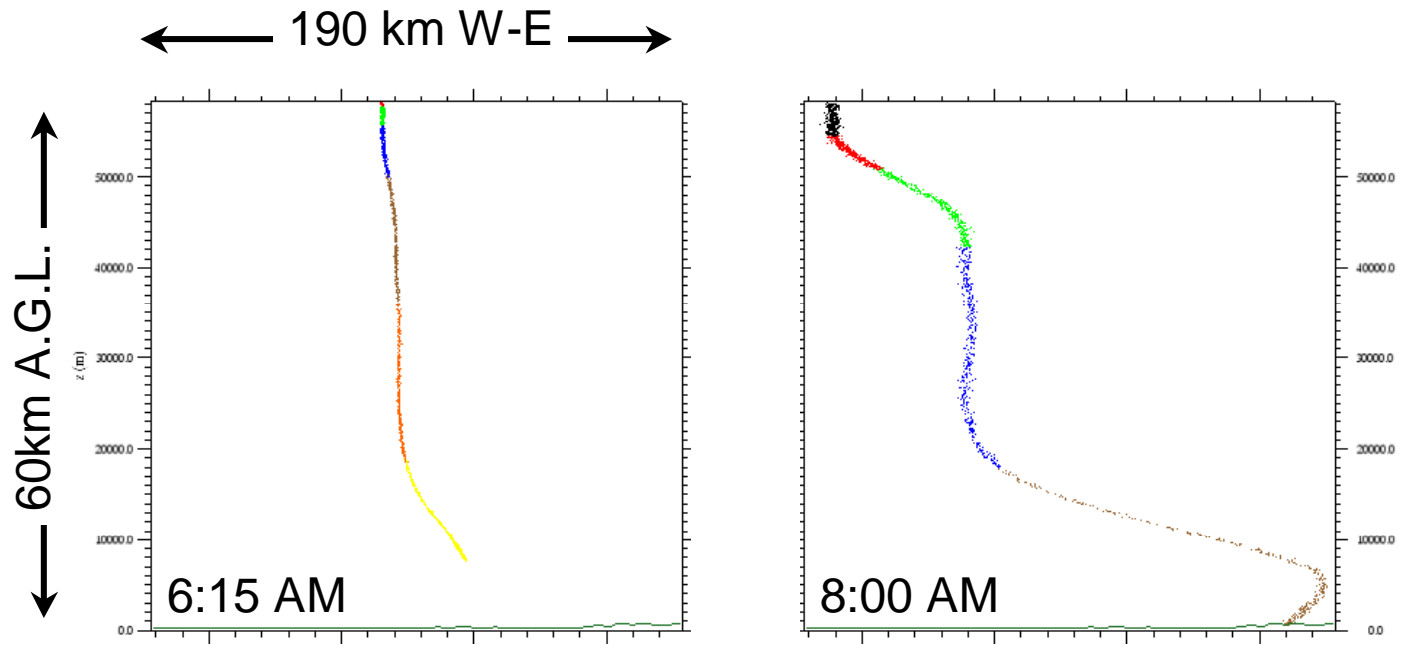

Figure 6. Side view (West to East) perspective on particles and deposition as modeled with the GEOS-4 dataset from release time of 6:00am to 8:00am September 15, 2002. Release height is 65km. The wind shear is very apparent from this perspective at different altitudes.

\section{Simulations with US Navy G2S Forecast and Climate Datasets}

After simulating a high altitude release at $65 \mathrm{~km}$ using the GEOS-4 data, we gained access from the US NRL to meteorological and climatological datasets for additional highaltitude analysis. Here, data were incorporated into the ADAPT assimilation model over a 1000 by 1000 square kilometer domain up to 80km for August 18, 2002 from 0000 Zulu to 1500 Zulu. The data from both sets were provided by Dr Doug Drob of US NRL in Washington, DC. The NRMLMSISE-00 climatological data is based on a 40-year 
historical database of upper atmospheric research measurements (Picone et al., 2002), while the G2S dataset has blended below 55km historical data for a particular date and time (Drob, 2003). The climatological dataset is more coarsely averaged over height than the G2S forecast data yielding a much smoother climatological wind field with altitude. Wind-component profiles in the center of the modeled domain for the two datasets are compared in Figure 7 ("u", east-west component) and Figure 8 ("v", north-south component). Note how the intensity of the jet stream at $\sim 10 \mathrm{~km}$ altitude in the climatology data is about half that observed in the G2S dataset. Additionally, the wind shear is less severe in the climatology data compared to the G2S data set. The differences between the G2S and climatological datasets can best be seen by comparing the Euclidean difference in wind vectors at the center of the simulated domain for 0000 Zulu and 1200 Zulu (Figure 9): a large difference in the winds is noticeable at the jetstream $(\sim 10 \mathrm{~km})$ with a difference in excess of $25 \mathrm{~m} / \mathrm{sec}(56 \mathrm{mph})$ and of a difference of nearly $15 \mathrm{~m} / \mathrm{sec}(34 \mathrm{mph})$ in the lower mesosphere $(\sim 50 \mathrm{~km})$.

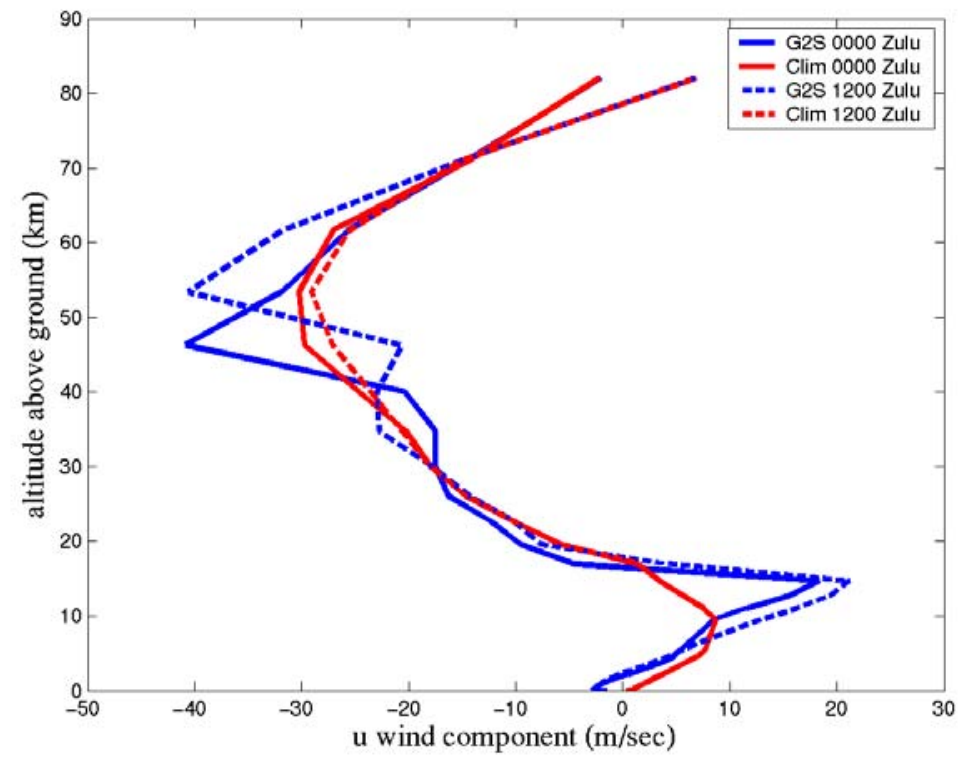

Figure 7. The east-west (u) component of the winds for the G2S forecast data at 0000 Zulu (blue solid line) and 0600 Zulu (blue dashed line); and for the climatological data at 0000 Zulu (red solid line) and 0600 Zulu (red dashed line). 


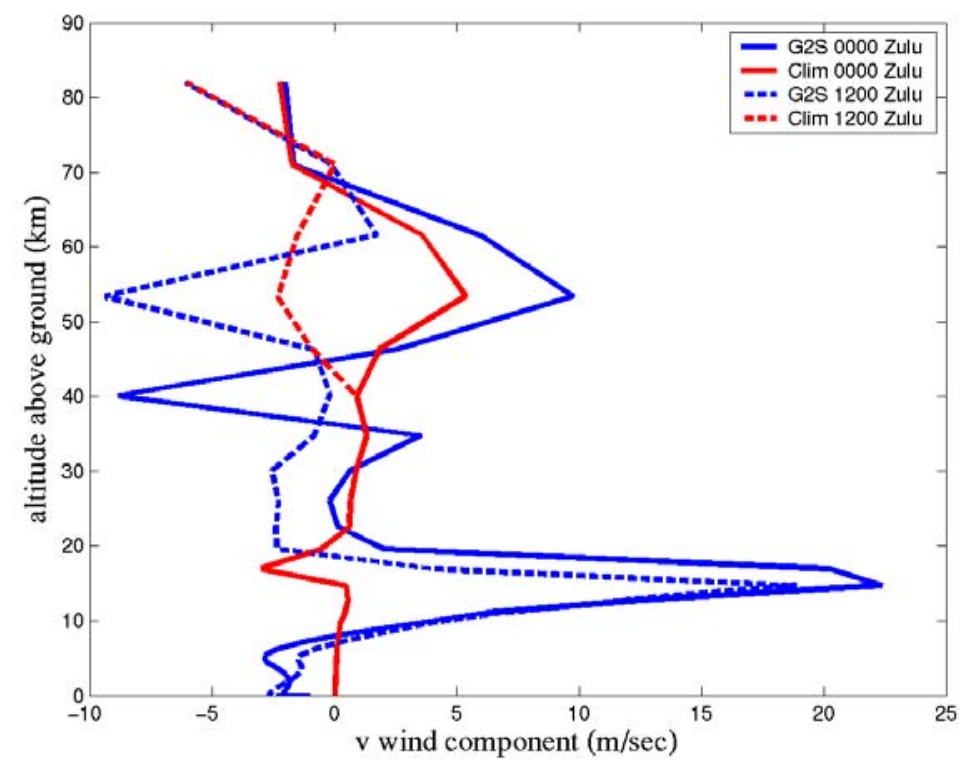

Figure 8. The north-south (v) component of the winds for the G2S forecast data at 0000 Zulu (blue solid line) and 0600 Zulu (blue dashed line); and for the climatological data at 0000 Zulu (red solid line) and 0600 Zulu (red dashed line).

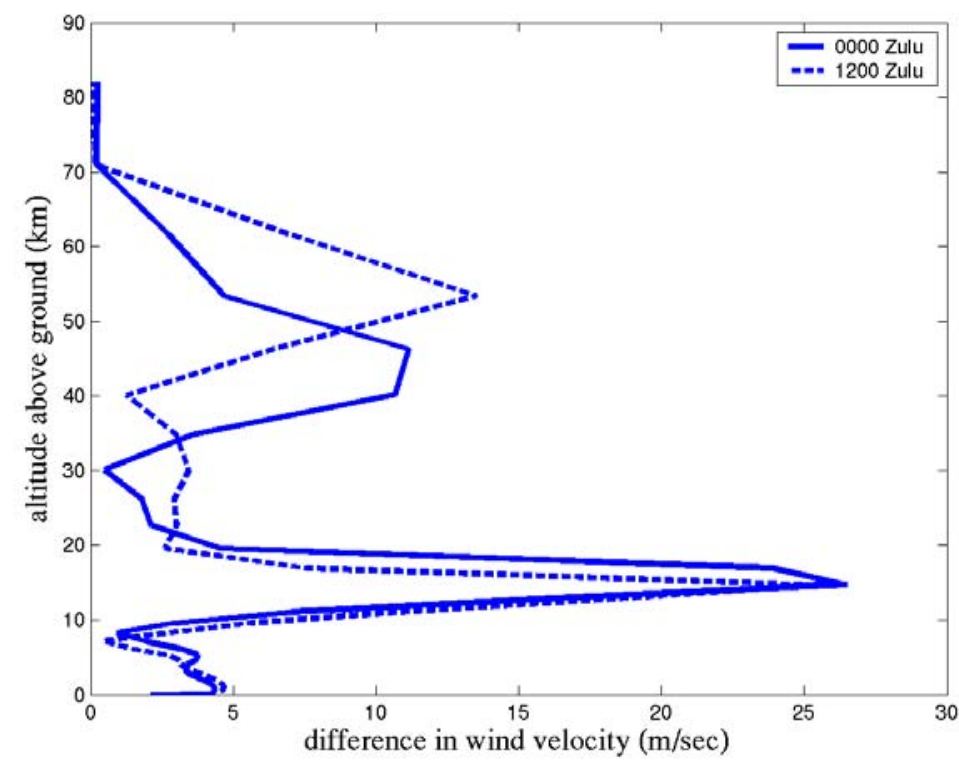

Figure 9. The Euclidean difference between the wind vectors at 0000 Zulu (solid line) and 1200 Zulu (dashed line). Note the large difference at the jet-stream level $(\sim 10 \mathrm{~km})$ and around the stratopause $(40-60 \mathrm{~km})$.

Predictably, the two wind field datasets yield very different deposition results for an $80 \mathrm{~km}$ release at 0500 Zulu of a uniform distribution of 10 to 3200 micron diameter particles (G2S deposition is outlined in black, climatological deposition is not outlined, Figure 10). At early times after release (0600 and 0700 Zulu, Figure 10), the heavier 
particles, 800 to 3200 microns, drop near the release point which is marked as a blue dot. These heavier particles tend to deposit mainly to the east of the release point as they are most influenced by the strong westerly jet stream at about $10 \mathrm{~km}$ altitude. At later times (see 0800, 0900, 1000, and 1100 Zulu, Figure 10) the lighter particles, 300 microns to 800 microns, tend to drop more to the west of the release point. This is because the lighter particles spend more time in the upper atmosphere and are more influenced by the high-altitude easterly winds between 15 and $70 \mathrm{~km}$ altitude. The critical difference in the two deposition plots is the fact that the forecast data is capturing small but important differences in the wind field structure. The G2S winds display a notably stronger and more southerly jet stream effect than the climate winds (Figure 8). The resulting deposition pattern is more northerly for the G2S simulation. It is worth noting the finer spatial and temporal detail of the G2S wind-structure (see Figure 7 and Figure 8). This increased wind detail results in greater overall dispersal of the particles in the G2S case due to the increased wind variability. Particles lighter than 300 microns disperse away from the 1000-by-1000 square-km domain, and do not deposit in the simulated time (many of these particles would eventually settle and deposit but outside of the modeled domain and at later times). It is important to note that a single day's worth of wind data is difficult for a proper evaluation of the differences in G2S and climate wind field datasets. A proper statistical analysis of a large set of historical cases needs consideration for proper quantification of these differences (e.g., Kaufmann and Weber, 1996; Glascoe et al., 2004).

\section{Summary}

A high altitude modeling capability developed under an LLNL-funded LDRD project was described in this document, and the implementation of the LLNL/NARAC codes were used for higher altitude data including GEOS-4 high altitude data from NASA, G2S forecast data from US NRL, and climatological data from US NRL. In this limited study funded by DTRA we accomplished our proposed goals which are, namely, the following: (1) we had discussions with NRL personnel and confirm data compatibility for use in NARAC; (2) we imported NRL data into the ADAPT atmospheric data assimilation model for runs on a test version of the NARAC Langrangian particle tracking code, LODI; and (3) we documented a limited assessment of the results of proof-of-concept simulations under time-varying meteorological forecasts and under climatological wind fields.

The NARAC simulations demonstrate the importance of modeling dynamic particle momentum, rarefied drag conditions and wind shear at higher altitudes. The notable difference in wind fields for the US NRL higher altitude data sets (G2S and climatological) results in large deviances in deposition patterns over large areas (hundreds of kilometers). Proper additional quantification of the differences of these data sets is necessary for a more complete analysis. 


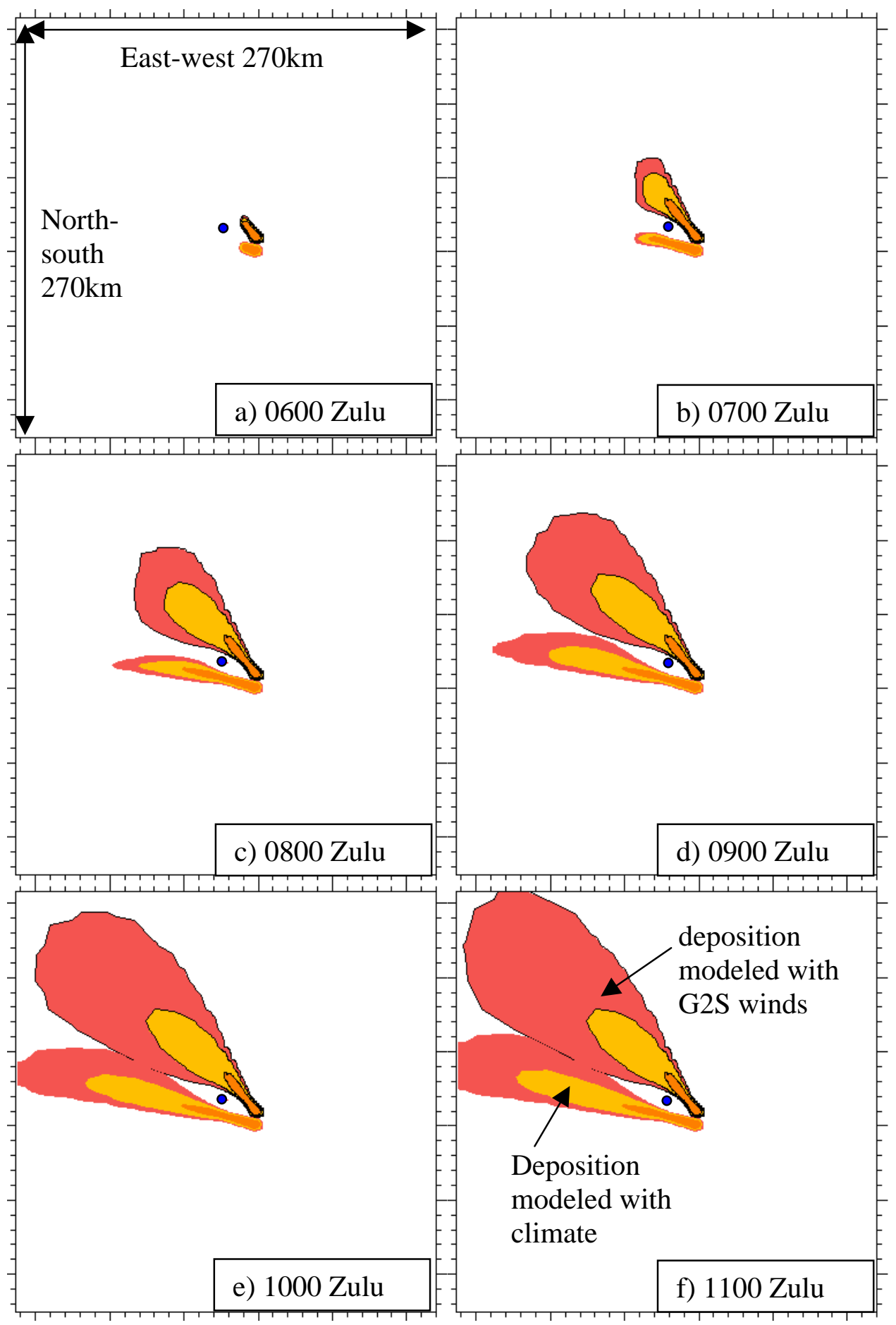

Figure 10. Plan views of deposition contours $(1 \mathrm{e}-9 \mathrm{~kg} / \mathrm{m} 2,1 \mathrm{e}-7 \mathrm{~kg} / \mathrm{m} 2,1 \mathrm{e}-6 \mathrm{~kg} / \mathrm{m} 2)$ from 0600 to 1100 Zulu simulated with a US Navy high-altitude meteorological forecast dataset (contours outlined in black) and a US Navy high altitude climatological dataset (no contour outline). The blue dot marks the $x-y$ location of the release point. 


\section{References}

Barad, M.L. (editor), 1958, Project Prairie Grass: A Field Program in Diffusion, Vols. 1 and 2, part of Geophysical Research Papers No. 59 series; also Report AFCRL-58235, Air Force Cambridge Research Center, July.

Cameron-Smith, P.J., Chuang, C., D.E. Bergmann, G. Bench, T. Cahill, S. Cliff, and P. Kelley. 2003. Analyzing the Long-Range Transport of Asian Aerosols Using an LLNL Atmospheric Model and CAMS/NOAA Measurements from Northern California. In: LDRD FY2003 Annual Report, Document UCRL-TR-113717-03.

Chin, H.-N. S., 1994: The impact of the ice phase and radiation on a midaltitude squall line. J. Atmos. Sci., 51, 3320-3343.

Chin, H.-N. S., Q. Fu, M. M. Bradley and C. R. Molenkamp, 1995: Modeling of a Tropical Squall Line in Two Dimensions: Sensitivity to Radiation and Comparison with a Midaltitude Case. J. Atmos. Sci., 52, 3172-3193.

Chin, H.-N.S., and L.G. Glascoe, 2004: COAMPS Application to Global and Homeland Security Threat Problems, LLNL Document, UCRL-TR-206584.

Crowe, C., M. Sommerfeld, and Y. Tsuji, 1998: Multiphase Flows with Droplets and Particles, CRC Press, New York.

DAO, 2002: Algorithm theoretical basis document, Data assimilation office, NASA's Goddard Space Flight Center.

Diehl, S.R. 1994. MESO Code Modifications and Simulations of High Altitude Dispersion. Kaman Sciences Corp., Colorado Springs, CO, K94-17U(R), pp.41.

Drob, D.P., 2003: Detailed specification of the atmosphere for infrasound propagation modeling, $25^{\text {th }}$ Seismic Research Review-Nuclear Explosion Monitoring: Building the Knowledge Base, Tuscon, Arizona, September 23-25.

Kaufmann, P. and R.O. Weber, 1996: Classification of mesoscale wind fields in the MISTRAL field experiment. J. Appl. Meteor., 35, 1963-1979.

Glascoe, L.G., R.E. Glaser, H.S. Chin, and G.A. Loosmore, 2004: Regional wind field classification employing cluster analysis, Proceedings for the $13^{\text {th }}$ Conference on the Application of Air Pollution Meteorology with Air and Waste Management Assoc, Vancouver, BC, Paper 7.2.

Harjenstein, G., 2000: Diffusive decay of Tropopause folds and the related crossTropopause mass flux. Monthly Weather Review, 128(8), 2958-2966.

Hodur, Richard M., 1997: The Naval Research Laboratory's Coupled Ocean/Atmosphere Mesoscale Prediction System (COAMPS). Monthly Weather Review, 125, 14141430. 
Nappo, C.J., 2002: An Introduction to Atmospheric Gravity Waves, Academic Press, San Diego.

Nasstrom, J.S., G. Sugiyama, J.M. Leone, Jr., and D.L. Ermak, 2000: A real-time atmospheric dispersion modeling system, Preprint, Eleventh Joint Conference on the Applications of Air Pollution Meteorology, Long Beach, CA, Jan. 9-14, 2000. American Meteorological Society, Boston, MA, 84-89.

Picone, J.M., A.E. Hedin, D.P. Drob, and A.C. Atkin, 2002: NRLMSISE-00 empirical model of the atmosphere: statistical comparisons and scientific issues, J. Geophys. Res., 107(A12), 1468.

Pluene, R., 1990: Vertical Diffusion in the Stable Atmosphere, Atmospheric Environment, 24A, 2547-2555.

Sugiyama, G. and S.T. Chan. A New Meteorological Data Assimilation Model for RealTime Emergency Response, 10th Joint Conference on the Applications of Air Pollution Meteorology. 1998. Phoenix, AZ: American Meteorological Society.

Wilks, D.S., 1995: Statistical Methods in the Atmospheric Sciences, Academic Press, New York. Wilks, D.S., 1995: Statistical Methods in the Atmospheric Sciences, Academic Press, New York. 
University of California

Lawrence Livermore National Laboratory

Technical Information Department

Livermore, CA 94551

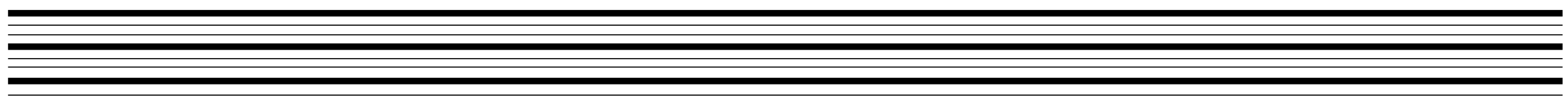

